\title{
Simultaneous detection of five different 2-hydroxyethyl DNA adducts formed by ethylene oxide exposure, using a high- performance liquid chromatography/electrospray ionisation tandem mass spectrometry assay.
}

Elaine M. Tompkins, Donald J.L. Jones, John H. Lamb, Debbie A. Marsden, Peter B. Farmer and Karen Brown.*

Cancer Biomarkers and Prevention Group, Department of Cancer Studies and Molecular Medicine, The Biocentre, University of Leicester, University Road, Leicester LE1 7RH, UK.

*Corresponding Author. Fax: 01162231840

E-mail: kb20@le.ac.uk 


\section{ABSTRACT}

A method has been developed for the simultaneous detection and quantitation of five different (2-hydroxyethyl)-DNA adducts (HE-DNA adducts) that could be formed as a result of exposure to ethylene oxide (EO). In addition to the major N7-HE-guanine (N7-HEG) adducts this assay can also measure the less prevalent but potentially more biologically significant N1-HE-2'-deoxyadenosine (N1-HEdA), $\mathrm{O}^{6}$-HE-2'deoxyguanosine $\left(\mathrm{O}^{6}\right.$-HEdG), $N^{6}$-HE-2'-deoxyadenosine $\left(N^{6}\right.$-HEdA) and $N 3$-HE-2'deoxyuridine adducts (N3-HEdU). The method involves the isolation of HE-adducts from the unmodified nucleosides by either neutral thermal hydrolysis or enzymatic digestion, followed by HPLC purification, before detection and quantification by liquid-chromatography tandem mass spectrometry (LC-MS/MS) using selective reaction monitoring (SRM). The limits of detection were in the range $0.5-25$ fmoles for each individual adduct, making this one of the most sensitive assays available for the detection of N7-HEG. To illustrate the possible applications of the assay, it has been employed in the measurement of endogenous/background and EO-induced HEadducts in a variety of DNA samples.

KEYWORDS: LC-MS/MS, SRM, 2-hydroxyethyl, ethylene oxide, DNA adducts. 


\section{INTRODUCTION}

Ethylene oxide (EO) is a widely used chemical intermediate and gaseous sterilant ${ }^{1}$, which is also formed endogenously through the metabolism of ethylene ${ }^{2,3}$ by cytochrome P450-dependant monooxygenases in vivo ${ }^{4,5}$. Possible endogenous sources of ethylene include lipid peroxidation ${ }^{6}$ and intestinal bacteria metabolism ${ }^{7}$, together with the oxidation of free methionine $e^{6,8}$ and haemoglobin products ${ }^{9}$. In contrast to ethylene, which has been designated as "not classifiable as to its carcinogenicity to humans", EO is categorised as "carcinogenic to humans" by the International Agency for Research on Cancer (IARC), based largely on findings from animal studies and sufficient evidence to support a relevant mechanism of carcinogenicity in humans ${ }^{1}$. For example, EO reacts directly with cellular macromolecules to form covalent 2hydroxyethyl (HE) adducts with both proteins and $\mathrm{DNA}^{2}$, without the need for prior metabolic activation and studies in various in vitro systems and animal models have shown that EO is capable of inducing mutations ${ }^{5,10,11}$, sister chromatid exchanges and chromosomal aberrations ${ }^{12}$. However, the current data is conflicting or inconclusive regarding whether exposure to EO actually increases the incidence of human cancers $^{13-16}$. Consequently, there is much interest in elucidating the mechanisms through which EO causes these effects and identifying appropriate mechanism-based biomarkers that can be monitored for human risk assessment purposes.

Alkyl epoxides react predominantly with strong nucleophilic endocyclic ring nitrogens of DNA bases, via an $\mathrm{S}_{\mathrm{N}} 2$ mechanism ${ }^{4}$. For EO, the principal site of 2'hydroxyethylation is the N7-position of guanine, forming N7-hydroxyethylguanine $(N 7-\mathrm{HEG})^{17}$, which is illustrated in Figure 1 alongside the other possible DNA adducts formed by $\mathrm{EO}^{18}$. Alkylation of the $N 7$ position of guanine produces a 
quaternary ammonium ion, leading to cleavage of the $N$-glycosydic bond ${ }^{19}$, which if not repaired can result in an apurinic (AP) site. N7-HEG adducts are not considered to be promutagenic themselves, although presence of AP sites during DNA replication could result in miscoding ${ }^{20,21}$. Being the predominant EO alkylation product however, measures of N7-HEG can provide a valuable biomarker of exposure. Very little is known about the properties of the other 2-hydroxyethyl DNA adducts, which together account for less than $5 \%$ of the reaction products when EO is incubated with DNA in vitro $^{2}$. It seems likely that if formed, they may contribute to the biological effects of $\mathrm{EO}$, given that $\mathrm{O}^{6}$-alkylguanine adducts have been widely demonstrated to be mutagenic $^{22}$. In addition, N3-HE-2'-deoxycytidine undergoes spontaneous hydrolytic deamination to form $\mathrm{N} 3$-HEdU ${ }^{23,24}$, which has been suggested as a potentially mutagenic adduct ${ }^{25}$ and adduction at the N1-position of adenine is proposed to be a miscoding lesion ${ }^{26,27}$.

A variety of methods for the detection and quantitation of EO-derived DNA adducts have been reported, however, virtually all published assays have focused solely on measurement of the major N7-HEG adduct, excluding the lesser formed adducts ${ }^{28,29}$. ${ }^{32}$ P-Postlabelling ${ }^{30-34}$ approaches can detect N7-HEG in control rat liver at levels of 1 adduct per $10^{7}$ nucleotides $^{33}$ and similar amounts have been detected in the lymphocytes of unexposed humans ${ }^{34}$. However, the assay procedure can be rather lengthy, it provides no structural information and the analysis is highly inefficient due to spontaneous depurination of the N7-HEG adduct, which must remain in the nucleotide form in order to be detectable. In a comparison of different immunoassay methods for N7-HEG detection ${ }^{35}$ an immunoslot blot assay was found to be the most sensitive, although the limit of detection (LOD) was in the region of 0.3 adducts per 
$10^{6}$, considerably higher than other methods. Furthermore, immunoassays require antibodies specific to the adduct in question and these are not currently available for any other HE-adducts, limiting detection to the major N7-HEG lesion. HPLC with fluorescence detection has been used to measure the dosimetry of N7-HEG in rodents and could also detect $\mathrm{O}^{6}$-HEGuanine and $N 3$-HEAdenine adducts in rats exposed to high doses $(300 \mathrm{ppm})$ of EO, but the technique lacked the necessary sensitivity to detect $\mathrm{O}^{6}$-HEG and N3-HEA in unexposed animals ${ }^{36}$. Mass spectrometry based methods afford greater specificity and the sensitivity of these systems is continually

improving ${ }^{37-39}$. As very little is known about the frequency and biological effects of the lesser formed HE adducts, we have developed and validated a novel, highly sensitive, and specific LC-MS/MS method for the simultaneous detection and quantitation of five adducts that can potentially be derived from ethylene oxide exposure. This is useful to the study of HE-DNA adducts as previous assays could only detect the N7-HEG adduct. We also demonstrate various applications of the assay; for the detection of levels of endogenous/ background HE adducts as well as adducts induced by EO treatment in samples including DNA extracted from the liver of control and treated rats.

\section{EXPERIMENTAL}

\section{Caution:}

EO is classified as a human carcinogen and should be handled with the appropriate precaution.

\section{Chemicals}


Ethylene oxide gas (99.8\% purity), nucleosides and DNA bases for the synthesis of adduct standards and the enzymes snake venom phosphodiesterase and DNase I were purchased from Sigma (Poole, Dorset, UK). The $\mathrm{O}^{6}-\mathrm{HEdG}$ adduct standard was kindly provided by Dr Didier Gasparutto (Laboratoire des Lésions des Acides Nucléiques, CEA Grenoble, France). $\left[{ }^{15} N_{5}\right]$-Labelled 2'-deoxynucleosides were from Spectra Stable Isotopes (Columbia, MD, USA) and HPLC solvents from Fisher Scientific (Loughborough, UK). Shrimp alkaline phosphatase was obtained from Roche (East Sussex, UK).

\section{Synthesis of DNA adduct standards}

Hydroxyethyl (HE)-nucleoside and base adducts were required as authentic standards for the LC-MS assay. It was envisaged that nucleoside adducts which readily depurinate, such as the $N 7-\mathrm{HEdG}$, would be more accurately and reliably quantified in the free base form, liberated by hydrolysis of adducted DNA, whilst for the more chemically stable adducts it would be more appropriate to quantify the nucleoside lesion, which could be isolated after DNA digestion. Therefore, a method was established which permitted simultaneous detection of specific ethylene oxide derived adducts in either the base (N7-HEG) or nucleoside (N1-HEdA, $N^{6}$-HEdA, $\mathrm{O}^{6}$ HEdG, N3-HEdU) form and these adducts were synthesised, along with two ${ }^{15} \mathrm{~N}$ labelled internal standards $\left(\left[{ }^{15} N_{5}\right]-N 7-\mathrm{HEG}\right.$ and $\left.\left[{ }^{15} N_{5}\right]-N 1-\mathrm{HEdA}\right)$, for use in the development and validation of the assay.

For the production of nucleoside adducts $\mathrm{dA}$, dU, and $\left[{ }^{15} N_{5}\right]-\mathrm{dA}, 2$ mmoles of each were dissolved in $\mathrm{H}_{2} \mathrm{O}(20 \mathrm{~mL})$ and reacted with $2.3 \mathrm{mM}$ EO for $18 \mathrm{~h}$ at $37^{\circ} \mathrm{C}$, then concentrated by freeze-drying. EO was condensed on ice and the required volume 
added directly to the dissolved nucleosides to obtain the correct concentration. To generate the N7-HEG base standards, guanosine (Gua or $\left[{ }^{15} N_{5}\right]$-Gua (1mmole)) was dissolved in $20 \mathrm{~mL}$ glacial acetic acid/ $\mathrm{H}_{2} \mathrm{O}(1: 1)$ and reacted with $2.3 \mathrm{mM}$ EO for $18 \mathrm{~h}$ at $37^{\circ} \mathrm{C}$, then freeze-dried. The residue was redissolved in $1 \mathrm{M} \mathrm{HCl}(10 \mathrm{~mL})$ and heated at $100^{\circ} \mathrm{C}$ for $1 \mathrm{~h}$, then concentrated to dryness under vacuum. The sample was then dissolved in $1 \mathrm{M} \mathrm{HCl}(4 \mathrm{~mL})$ and the $\mathrm{pH}$ adjusted to 4.0 , using $5 \mathrm{M} \mathrm{NaOH}$ and $\mathrm{H}_{2} \mathrm{O}$, in a final volume of $30 \mathrm{~mL}$.

The products of each EO reaction (base and nucleosides) were separated by preparative HPLC, using a water:methanol gradient: 5-80\% $\mathrm{MeOH}$ over 25 min at a flow rate of $10 \mathrm{~mL} / \mathrm{min}$, using a Hypersil BDS $\mathrm{C}_{18}$ column $(250 \times 21.2 \mathrm{~mm}, 5 \mu$, Phenomenex, Macclesfield, UK). Authentic standards were used to identify unreacted starting material and all other significant peaks were collected and evaporated to dryness for structural analysis, to identify those fractions containing 2-HE adducts. In some cases it was necessary to perform a second HPLC purification on the collected fractions and this was carried out using identical conditions.

\section{Structural Characterisation of HE-DNA adducts}

The UV spectrum was obtained for each potential adduct containing fraction (nucleoside and base) using a Hitachi U-3010 spectrophotometer (Hitachi, Wokingham, Berkshire) and compared to available published data for ethylene oxide DNA adducts ${ }^{18}$. Samples with UV spectra consistent with the addition of a hydroxyethyl group were subject to MS analysis. 
HPLC fractions were analysed by mass spectrometry using a Micromass Quattro BioQ, equipped with a pneumatically assisted electrospray source (Waters, Hertfordshire, UK). The mass spectrometer was tuned using a thymidine standard in $\mathrm{MeOH}(5$ pmoles $/ \mu \mathrm{L})$. Each HPLC peak residue was redissolved in methanol and analysed by continuous infusion. Analysis was carried out in the positive ion mode, and the molecular mass of the components of each peak was determined using a total ion scan (Figure 2). The structure of each potential HE-DNA adduct standard was further confirmed by MS/MS, and compared to the spectra for the fully characterized adducts published by Li et al. ${ }^{18} \mathrm{UV}$ spectrophotometry was then used to determine the concentration of each of the standards, using published wavelengths and extinction coefficients $^{18}$.

The reaction of EO with $\mathrm{dA}$ produced two different 2-hydroxyethyl adducts and MS/MS analysis of both fractions produced identical spectra, each containing the predicted $[\mathrm{M}+\mathrm{H}]^{+}$ion at $\mathrm{m} / \mathrm{z} 296$. However, the fractions varied significantly in their chromatographic properties; the first eluted at $13.5 \mathrm{~min}$ and the second, at $18.2 \mathrm{~min}$ on the HPLC separation system, indicating different sites of hydroxyethylation. In order to identify the individual adducts isolated, a small aliquot of each HPLC fraction was removed and $\mathrm{NaOH}(1 \mathrm{M})$ was added to increase the $\mathrm{pH}$ of the solution to 12 . After incubation at $37^{\circ} \mathrm{C}$ for $18 \mathrm{~h}$ the samples were neutralised with $\mathrm{HCl}(1 \mathrm{M})$ and the resulting products analysed by HPLC. The retention time of peak A remained at 13.5 min, however peak B appeared to have structurally rearranged into peak A, suggesting that peak B was $N 1-\mathrm{HEdA}$ and peak A was $N^{6}-\mathrm{HEdA}^{40}$. 


\section{Isolation and LC-MS/MS analysis of HE-DNA adducts.}

Typically, 1 pmole of a base adduct internal standard, $\left[{ }^{15} N_{5}\right]-N 7-H E G$, was added to each DNA sample (50-100 $\mu \mathrm{g})$, which was then depurinated by heating to $100^{\circ} \mathrm{C}$ for 30 min. Preferentially released adducted purines were separated from the DNA by centrifugation through Microcon filters (3,000 MW, YM-3, Millipore, Watford, UK) for $30 \mathrm{~min}$ at $13,000 \mathrm{rpm}(28,000 \mathrm{~g})$; N7-HEG passes through in the filtrate whilst intact DNA is retained and can be recovered from the filter, by inversion, for subsequent digestion. A second internal standard $\left[{ }^{15} N_{5}\right]-N 1-\mathrm{HEdA}(1$ pmole $)$ was then added to the recovered DNA, which was dried down under vacuum, redissolved in 40 $\mathrm{mM}$ tris- $\mathrm{HCl}, 10 \mathrm{mM} \mathrm{MgCl}_{2}, \mathrm{pH} 8.5$ and digested with snake venom phosphodiesterase (0.05 U), DNase I (10 U) and shrimp alkaline phosphatase (2 U) for $2 \mathrm{~h}$ at $37^{\circ} \mathrm{C}$. Enzymes were removed by centrifugation $(30 \mathrm{~min}, 13,000 \mathrm{rpm}$, 28,000g) through Microcon YM-3 filters (Millipore), the samples were then concentrated to dryness prior to HPLC purification.

HE-DNA nucleoside adducts contained in the DNA digests were separated from the unmodified nucleosides by HPLC on a Phenomenex Luna $\mathrm{C}_{18}$ column $(5 \mu, 250 \times 2.1$ mm, Phenomenex, Macclesfield, UK), using a linear $0.1 \%$ acetic acid:methanol gradient (increasing from $0-35 \% \mathrm{MeOH}$ over $25 \mathrm{~min}, 35-75 \% \mathrm{MeOH}$ by $32.5 \mathrm{~min}$, and finally $0 \% \mathrm{MeOH}$ by $43 \mathrm{~min}$, at a flow rate of $0.2 \mathrm{~mL} / \mathrm{min}$ ). Nucleoside adducts elute in the following fractions: 14-16 $\min \left(N^{6}-\mathrm{HEdA}\right), 21-23 \min (N 3-\mathrm{HEdU})$ and 25-32 $\min \left(\left[{ }^{15} N_{5}\right]-N 1-\mathrm{HEdA}, N 1-\mathrm{HEdA}\right.$ and $\mathrm{O}^{6}$-HEdG). All adducts are well resolved from the normal, unadducted nucleosides which elute around $20-23$ min, except for N3-HEdU which co-elutes with dT. This system was also used to isolate the N7-HEG (and $\left[{ }^{15} N_{5}\right]-N 7-H E G$ ) from other types of adducted purines which may be present in 
the collected filtrate. This base adduct elutes between 5-8 min. A different HPLC solvent gradient was used to further separate $N 3$-HEdU from the unmodified dT, consisting of a linear $0.1 \%$ acetic acid:methanol gradient (increasing from $0-25 \%$ $\mathrm{MeOH}$ over $50 \mathrm{~min}$, at a flow rate of $0.2 \mathrm{~mL} / \mathrm{min}$ ). Using this system, dT elutes at 26 min and N3-HEdU at $27.5 \mathrm{~min}$, allowing the hydroxyethylated dU to be collected separately. For each original DNA sample, all fractions containing the desired base and nucleoside HE-adduct fractions were then combined and evaporated to dryness prior to LC-MS/MS analysis. To ascertain whether stability of the nucleoside HEadducts was affected by the depurination procedure employed to isolate the N7-HEG base lesions, untreated plasmid DNA $(100 \mu \mathrm{g})$ was spiked with 500 fmoles of each of nucleoside adduct standard. Each sample $(n=3)$ was divided in half and one aliquot was heated to $100^{\circ} \mathrm{C}$ for $30 \mathrm{~min}$. Both samples were then digested, the adducts isolated by HPLC and then quantified by LC-MS/MS analysis as described below.

Samples were analysed for the presence of the five hydroxyethyl adducts (N7-HEG, N3-HEdU, $N^{6}$-HEdA, $N 1$-HEdA and $\mathrm{O}^{6}$-HEdG) in a single LC-MS/MS run, using a system consisting of a Waters Alliance 2695 separations module interfaced to a Waters Quattro Ultima Pt (Waters, Manchester, UK), operated in the positive ion mode. Samples were injected via a $100 \mu \mathrm{L}$ loop onto a Supelcosil $\mathrm{C}_{18}, 250$ x $2.1 \mathrm{~mm}$, $5 \mu$ column (Sigma, Poole, UK) and separated using an isocratic system of $40 \%$ $\mathrm{MeOH}$ in $0.5 \%$ acetic acid, at a flow rate of $0.12 \mathrm{~mL} / \mathrm{min}$. The eluate from the HPLC was introduced directly into the mass spectrometer. The source temperature was maintained at $120^{\circ} \mathrm{C}$ and the desolvation temperature at $350^{\circ} \mathrm{C}$, nitrogen was used as the desolvating gas at a flow rate of $550 \mathrm{~L} / \mathrm{hr}$. The cone voltage was $98 \mathrm{~V}$ and the collision energy was $17 \mathrm{eV}$ for all transitions measured. Each sample was dissolved in 
$40 \% \mathrm{MeOH}$ in $0.5 \%$ acetic acid $(40 \mu \mathrm{L})$ and duplicate injections of $15 \mu \mathrm{L}$ were performed for each individual sample analysed. The mass spectrometer was operated in the selected reaction monitoring (SRM) mode and measured the following transitions simultaneously: $\mathrm{m} / \mathrm{z} 312$ to $\mathrm{m} / \mathrm{z} 196$ for $\mathrm{O}^{6}-\mathrm{HEdG}, \mathrm{m} / \mathrm{z} 301$ to $\mathrm{m} / \mathrm{z} 185$ for $\left[{ }^{15} N_{5}\right]-H E d A, m / z 296$ to $\mathrm{m} / \mathrm{z} 180$ for both $N 1$-HEdA and $N^{6}-\mathrm{HEdA}$, which all correspond to the loss of a 2-deoxyribose from positively ionised 2'deoxyribonucleoside adducts i.e., $[\mathrm{M}+\mathrm{H}]^{+} \rightarrow[\mathrm{M}+\mathrm{H}-116]^{+}$and $\mathrm{m} / \mathrm{z} 295$ to $\mathrm{m} / \mathrm{z} 179$ for N3-HEdU, corresponding to the loss of 2'-deoxyribose from the sodiated adduct $[\mathrm{M}+\mathrm{Na}]^{+} \rightarrow[\mathrm{M}+\mathrm{Na}-116]^{+}$. The measurement of $\mathrm{m} / \mathrm{z} 201$ to $\mathrm{m} / \mathrm{z} 157$ for $\left[{ }^{15} N_{5}\right]-N 7-$ HEG and $\mathrm{m} / \mathrm{z} 196$ to $\mathrm{m} / \mathrm{z} 152$ for $N 7-\mathrm{HEG}$, corresponds to the measurement of the [adducted base $+\mathrm{H}]^{+}$to [unadducted base $\left.+\mathrm{H}\right]^{+}$.

The levels of nucleoside HE-DNA adducts in each sample were determined by measuring the ratio of the peak area of each individual HE-DNA adduct to that of the $\left[{ }^{15} N_{5}\right]-N 1-H E d A$ internal standard, whilst $N 7-$ HEG was measured relative to $\left[{ }^{15} N_{5}\right]-$ $N 7-\mathrm{HEG}^{41}$, then the values were converted to adducts/ $10^{8}$ nucleotides. Figure 3 gives an overview of the assay procedure for the isolation and quantitation of HE-adducts.

\section{Validation Parameters}

Linearity of calibration was determined by measuring the ratio of peak areas of the four different HE-adduct standards to the $\left[{ }^{15} N_{5}\right]-N 1-H E d A$ internal standard and the HE-base standard to the $\left[{ }^{15} N_{5}\right]-N 7-H E G$ internal standard. For validation of the assay, double the amount was prepared and half was injected onto the column. Calibration standards ranging from 0.5 - 500 fmoles were run three times each day over a three day period. The daily mean peak ratio of HE-adduct standard to internal standard was 
used to construct a calibration line. A correlation coefficient was calculated to confirm linearity for each of the five different HE-adducts.

Intra-day precision was evaluated by analysis of calibration standards for the three injections of each concentration for each of the five HE-adducts. This was calculated in the same way over a three day period and determined by the relative standard deviation (R.S.D = S.D./mean concentration) x 100. The limit of quantitation (LOQ) was defined as a signal to noise baseline ratio of 7:1.

\section{Measurement of HE-DNA adducts in DNA.}

A variety of samples were analysed for the presence of HE-DNA adducts to demonstrate potential applications of the LC-MS/MS assay. Background levels of adducts were measured in commercially available control calf thymus (CT) DNA, and liver DNA from an untreated (control) male F-344 rat, provided from another study as described by Marsden, et $a .^{42}$ In addition, adducts were measured in a pSP189 plasmid DNA isolated from E.coli bacteria ${ }^{43}$ that had been exposed to EO in vitro, by reacting with $10 \mathrm{mM} \mathrm{EO}$ for $24 \mathrm{~h}$ at $37^{\circ} \mathrm{C}$ in water. HE-DNA adducts were isolated from the three types of DNA, purified by HPLC and quantitated by LC-MS/MS as detailed above.

\section{RESULTS AND DISCUSSION}

We have developed a sensitive and specific method allowing the simultaneous detection and quantitation of multiple HE-DNA adducts formed as a result of EO exposure. The standards were synthesised by reaction of nucleosides with EO and purification of the reaction products by HPLC. The reaction between $\mathrm{dU}$ and EO 
resulted in one major product, in addition to unreacted dU, as detected by HPLC-UV (Figure 2A) and MS analysis indicated that this peak had the predicted $\mathrm{m} / \mathrm{z}$ of 273 , consistent with N3-HEdU. This structure was further confirmed by MS/MS analysis, containing fragment ions equivalent to $\mathrm{N} 3$-HEU and the 2'-deoxyribose. EO is known to react with both the $N 1$ - and $N^{6}$ - position of dA, as well as the $N 3$-position, although this adduct is labile and can readily depurinate. On reaction of EO with dA, 2 different adduct peaks were evident by HPLC-UV analysis, which both resulted in molecules with $\mathrm{m} / \mathrm{z}$ of 296 and produced the same dissociation spectra, when analysed by MS/MS (Figure 2B). Both are consistent with a hydroxyethylated dA adduct. Incubation of each adduct fraction with $\mathrm{NaOH}$ caused the later eluting peak $\mathrm{B}$ to convert into peak A. This confirmed that peak B was N1-HEdA and peak A was $N^{6}$ HEdA, as in the presence of a strong base, a group at the N1- position can rearrange onto the $N^{6}$ - position, in a reaction known as the Dimroth rearrangement ${ }^{44} \cdot\left[{ }^{15} \mathrm{~N}_{5}\right]-N 1$ HEdA was produced from an analogous reaction with $\left[{ }^{15} \mathrm{~N}_{5}\right]$-labelled dA by isolating the HPLC fraction with a similar retention time to that of N1-HEdA and the identity was confirmed by MS/MS. N7-HEG and $\left[{ }^{15} N_{5}\right]-N 7-\mathrm{HEG}$ base adducts were synthesised by the reaction of guanosine with EO, then removal of the ribose group by acid hydrolysis. HPLC analyses of the reaction products revealed one major product peak in each reaction with similar retention times, which was then collected and the structures confirmed by ESI-MS, revealing the expected protonated molecules at $\mathrm{m} / \mathrm{z} 196$ and $\mathrm{m} / \mathrm{z} 201$ for the $N 7$-HEG and $\left[{ }^{15} \mathrm{~N}_{5}\right]$-labelled standards, respectively. The structures of these two adducts were further confirmed by LC-MS/MS analysis, since the spectra produced by the dissociation of $N 7-\mathrm{HEG}(\mathrm{m} / \mathrm{z}=196)$ is comparable to that reported by Liao et al. ${ }^{45}$ (Figure 2C). 
Even though the assay utilised SRM as the analysis method, which allows the selective monitoring of a number of specific transitions, in any DNA sample HEadducts would be present at extremely low levels relative to the normal, unmodified nucleosides. Therefore, enrichment procedures were necessary to minimise interference with adduct quantitation and obtain the maximum sensitivity. The labile nature of the N7-HEG adduct was exploited in the selective isolation of this adduct from the intact DNA by thermal depurination and filtration. In addition to the desired adduct, the filtrate from this procedure would be expected to contain other depurinating lesions present endogenously or produced by EO exposure, such as N3HEA. Although other published assays analyse N7-HEG levels directly after hydrolysis and filtration ${ }^{43,45,48}$, this approach resulted in inconsistent measures of the nucleoside adducts, probably due to the presence of other base lesions or contaminants in the filtrate causing interference or signal suppression during LCMS/MS analysis. Therefore, in order to enable the accurate quantitation of multiple HE-adducts simultaneously, it was necessary to purify the N7-HEG and $\left[{ }^{15} N_{5}\right]$ labelled internal standard by HPLC prior to analysis.

The remaining HE-adducts were isolated by enzymatic digestion of the DNA recovered from the microcon filter, which is then separated by HPLC using a system capable of resolving the HE-adducts of interest from unmodified nucleosides (Figure 4), with the exception of N3-HEdU, which co-elutes with dT and is isolated by a further HPLC purification step. The addition of a nucleoside adduct internal standard $\left[{ }^{15} N_{5}\right]-N 1-H E d A$ prior to digestion accounts for losses due to subsequent sample handling of the unlabeled analogue, particularly during the HPLC separation step. LC-MS/MS analysis of nucleoside HE-adduct standards subjected to thermal 
hydrolysis prior to going through the assay procedure, confirmed the depurination step did not cause loss of these adducts due to degradation. This was evidenced by the fact adduct levels for control and hydrolysed samples varied by no more than $\pm 5 \%$.

The collected fractions from the preparative HPLC runs are then combined and analysed for the presence of the 5 different HE-adducts simultaneously by LCMS/MS, by measuring a specific transition for each adduct. For nucleoside adducts, the optimum transition was found to be dissociation of the adducted nucleoside (or equivalent sodiated species for N3-HEdU) into adducted base through loss of the sugar moiety, whilst for base adducts, dissociation to the base as a consequence of loss of the 2-hydroxyethyl group was most suitable. The best possible separation conditions and solvent system were established using the synthetic standards, and a Supelcosil $\mathrm{C}_{18}, 250 \times 2.1 \mathrm{~mm}, 5 \mu$ column, eluted with an isocratic mobile phase of $40 \% \mathrm{MeOH}$ in $0.5 \%$ acetic acid, was found capable of providing the maximum overall sensitivity with optimum peak shape and retention time (Figure 5A). N3-HEA, N3-HEdT and N3-HEdC were not incorporated into this assay but could however be introduced if required.

\section{Assay Validation}

In order to validate this assay, the following criteria were determined: linearity, precision, repeatability, inter-day variability, intra-day variability and the LOQ. Linearity, inter-day variability, repeatability and the LOQ were determined by the construction of a series of calibration lines (Figure 5B). The calibration curves produced from data obtained over the 3 day period were linear in the range 0.5-500 fmoles with a correlation coefficient $\mathrm{R}^{2} \geq 0.99$ for each individual adduct. Calculation 
of the R.S.D. for each concentration of individual HE-adducts was used to determine the inter-day precision of the developed assay, which was found to be $\leq 20 \%$. The limits of quantitation were determined as 0.5 fmoles injected onto the column for N7HEG and N1-HEdA, 5 fmoles for $\mathrm{O}^{6}$-HEdG and $N^{6}$-HEdA and 25 fmoles for N3HEdU. Measurement of N3-HEdU will always be an approximate value as an internal standard is ideally required to compensate for losses due to the additional HPLC step.

\section{Quantitation of HE-DNA adduct levels in DNA.}

Very little is known about the formation or biological consequences of HE-DNA adducts apart from the major N7-HEG lesion. Although, based on evidence from in vitro binding studies, the other potential HE-adducts account for a small proportion of total adduct formation by EO, and it is possible that under some circumstances they may be present at significant levels in vivo. The development of this assay provides, for the first time, a method that could potentially detect these adducts in DNA samples from exposed animals, humans or cultured cells, to determine whether they are formed and at what levels, using just a single DNA sample. The assay can also be applied to mechanistic studies, for example in combination with the supF forward mutation assay, which would allow mutagenic potency to be related to HE-DNA adduct profiles.

In order to demonstrate the possible applications of this assay, we have analysed levels of endogenous/background and EO-induced HE-adducts in various types of DNA as shown in Table 1 and Figure 6. The additional peaks present in the channels for $N 1-\mathrm{HEdA}$ and $\mathrm{O}^{6}$-HEdG are artefactual. MS/MS analysis suggests that they are related to the adducts and it is possible that they could be corresponding residual 
nucleoside N3-HEA and N7-HEG adducts. N7-HEG was detected in liver DNA from control rats at levels of $\sim 8$ adducts $/ 10^{8}$ nucleotides, which is comparable with that found by $\mathrm{Wu}$ et al., who reported endogenous adduct levels in the range of 5-8 adducts $/ 10^{8}$ nucleotides ${ }^{46}$ and similar to the $1-3.5$ adducts $/ 10^{8}$ nucleotides described in the Marsden study ${ }^{43}$. The DNA from the livers of rats treated with $1.5 \mathrm{mg} / \mathrm{kg}$ was also analysed (data not shown) but N7-HEG was still the only HE-adduct detected, suggesting that this dose is not high enough to induce the formation of N1-HEdA and $\mathrm{O}^{6}$-HEdG, or that they are formed but at a limit that is below the LOD of this assay. In untreated CT DNA, N7-HEG was the only HE-adduct detected, at background levels of $\sim 10$ adduct $/ 10^{8}$ nucleotides. For there to be endogenous/background adducts present in commercially available DNA is not unexpected, for example C8-(1hydroxyethyl)-guanine adducts have previously been reported in $\mathrm{CT} \mathrm{DNA}^{47}$. $\mathrm{O}^{6}$ HEdG has previously been detected and measured in different rat tissues by fluorescence-HPLC at approximate levels of 3 adducts $/ 10^{7}$ nucleotides but only after 2 weeks of exposure to $300 \mathrm{ppm} \mathrm{EO}^{11}$. In this study, $\mathrm{O}^{6}-\mathrm{HEdG}$ was not detected in any of the control DNA samples but exposure of pSP189 plasmid to a high concentration of EO $(10 \mathrm{mM})$ over a $24 \mathrm{~h}$ period, induced measurable levels of $\mathrm{O}^{6}$ HEG $\left(\sim 575 / 10^{8}\right.$ nucleotides $)$, as shown in Figure 6 , whilst also increasing the total N7-HEG and N1-HEdA to 415166 and 24216 adducts $/ 10^{8}$ nucleotides, respectively. N1-HEdA has only previously been observed in DNA treated with ${ }^{14} \mathrm{C}$-EO in vitro ${ }^{17}$, and only quantitated after a large-scale $50 \mathrm{mM}$ reaction of EO with CT DNA ${ }^{18}$.

More recently, the method of choice for the detection of N7-HEG adducts has been LC-MS. Leclerq et al., described an assay using LC-MS with single ion monitoring which achieved an LOD of 1 pmole injected onto the column, and measured 3 N7- 
HEG adducts $/ 10^{8}$ nucleotides in DNA from blood exposed to EO in vitro ${ }^{48}$. A similar method was published by Liao et al., with an LOD of 128 fmoles and the authors also demonstrated that using LC-MS/MS with SRM detection improved the sensitivity, decreasing the LOD further to 16 fmoles $^{45}$. In comparison, the highest LOD of the five HE-adducts analysed in this study is 25 fmoles injected onto the column. The most sensitive published method to date for the detection of N7-HEG appears to be the Gas Chromatography-Electron Capture-Mass Spectrometry method described by Wu et al., which had an LOD of 600 amoles $^{46}$. The assay described here is slightly more sensitive, for both N7-HEG and N1-HEdA, with an LOD of 500 amoles, and has the advantage that it does not require the production of a pentafluorobenzyl-N7-HEG derivative as part of the sample preparation step.

In developing an LC-MS/MS method for the simultaneous measurement of a number of different DNA adducts there is inevitably a compromise in sensitivity in order to achieve detection of all five HE-adducts. However, the LOD for the N7-HEG adduct is still more sensitive than any previous published method and with advances in technology, for example nanospray or ultra high pressure HPLC (UPLC), the sensitivity may be further improved in the future. In addition, if one wished to study any single HE-adduct specifically then the current assay could be tailored in favour of that particular adduct by slight alteration of the MS conditions to maximise the sensitivity for the adduct of interest. Multi-adduct analysis is becoming a more common approach for the study of the effects of chemical carcinogens; recently, Brink et al., have described a method for the determination of three promutagenic adducts formed as a result of exposure to dimethylnitrosamine, ${ }^{49}$ and an assay for the quantification of four structurally different adducts caused by oxidative stress has 
been reported by Churchwell et al. ${ }^{50}$ Since most chemical carcinogens form a variety of lesions, it is more informative to quantitatively determine the adduct profile rather than focus on a single adduct and these methods make this approach possible in a rapid and sensitive manner.

\section{Conclusion}

In summary, a sensitive and selective LC-MS/MS assay has been developed and validated for the simultaneous detection and quantitation of five different HE-DNA adducts that can be formed as a result of EO exposure. This allows a more comprehensive study of HE-adduct formation which has not previously been possible. To demonstrate its utility, this assay has so far been employed in the measurement of endogenous/background levels of DNA adducts in unexposed calf thymus and rat liver DNA, as well as EO-induced lesions in pSP189 plasmid DNA, and has the potential to be applied to the measurement of HE-DNA adducts from a wide variety of in vivo and in vitro studies to further our understanding of the significance of endogenous/background and exogenous HE-DNA adducts.

\section{ACKNOWLEDGMENT}

This work was funded by the Lower Olefins Sector Group and the Ethylene Oxide and Derivatives Sector Group of the European Chemical Industry Council (Cefic) and the Olefins Panel of the American Chemistry Council.

FIGURE CAPTIONS 
Figure 1: The different possible HE-adducts that can be produced as a result of ethylene oxide reaction with DNA. Adducts are shown in their base form.

Figure 2: Characterisation of synthesised HE-DNA adducts. HPLC purification of the reaction products are shown, with the corresponding ESI-MS/MS spectra for the product peak inserted. The separation of N3-HEdU from unmodified nucleoside is shown in (A). (B) shows a typical ESI-MS/MS spectra for $\mathrm{N}^{6}$-HEdA, which is identical to that produced by N1-HEdA (not shown), (C) shows the purification and characterisation of N7-HEG.

Figure 3: Scheme depicting the sample preparation steps prior to LC-MS/MS analysis.

Figure 4: HPLC chromatogram demonstrating the separation of HE-nucleoside adducts from unmodified nucleosides, using the conditions employed for the isolation of nucleoside HE-adducts. Synthetic adduct standards have been used to produce this trace for illustrative purposes; in a typical digested DNA sample HE-adducts would not usually be present at detectable levels and fractions would be collected on the basis of retention time.

Figure 5: Panel A shows a typical LC-MS/MS chromatogram resulting from the simultaneous measurement of 500 fmoles of each individual adduct standard. Panel B illustrates calibration lines for each of the five HE-DNA adduct standards that were used to validate the LC-MS/MS assay. 
Figure 6: Representative LC-MS/MS chromatograms from the analysis of liver DNA from a control F-344 rat (A) and pSP189 plasmid DNA reacted with 10 mM EO in vitro $(\mathbf{B})$. 
<smiles>Nc1nc2ncn(CCO)c2c(=O)[nH]1</smiles><smiles>Nc1ncn(CCO)c2ncnc1-2</smiles><smiles>Nc1nc(OCCO)c2nc[nH]c2n1</smiles><smiles>N=c1c2nc[nH]c2ncn1CCO</smiles><smiles>Cc1c[nH]c(=O)n(CCO)c1=O</smiles><smiles>OCCNc1ncnc2[nH]cnc12</smiles><smiles>CC(C)CCn1c(N)ccnc1=O</smiles>

Figure 1 

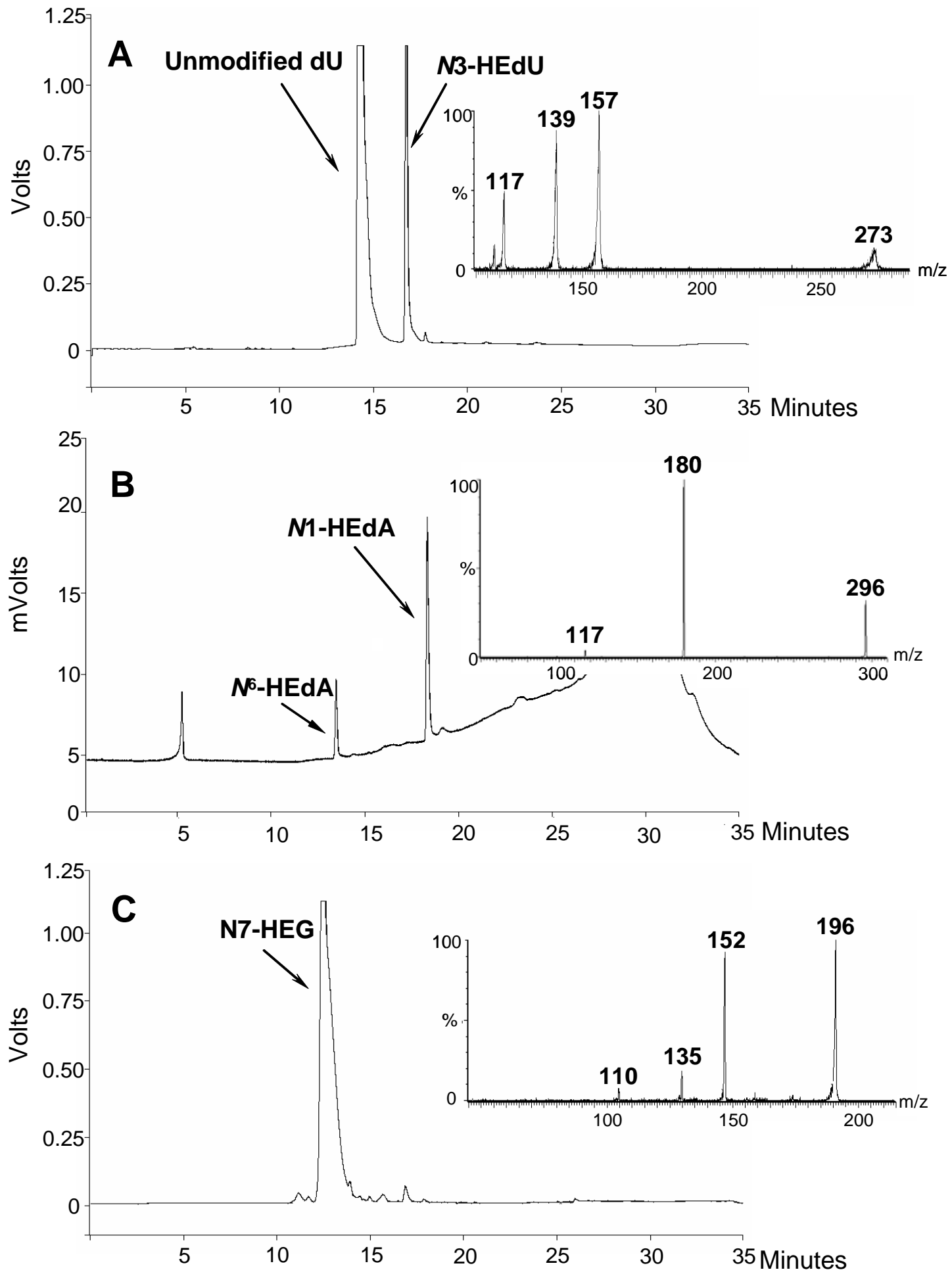

Figure 2 


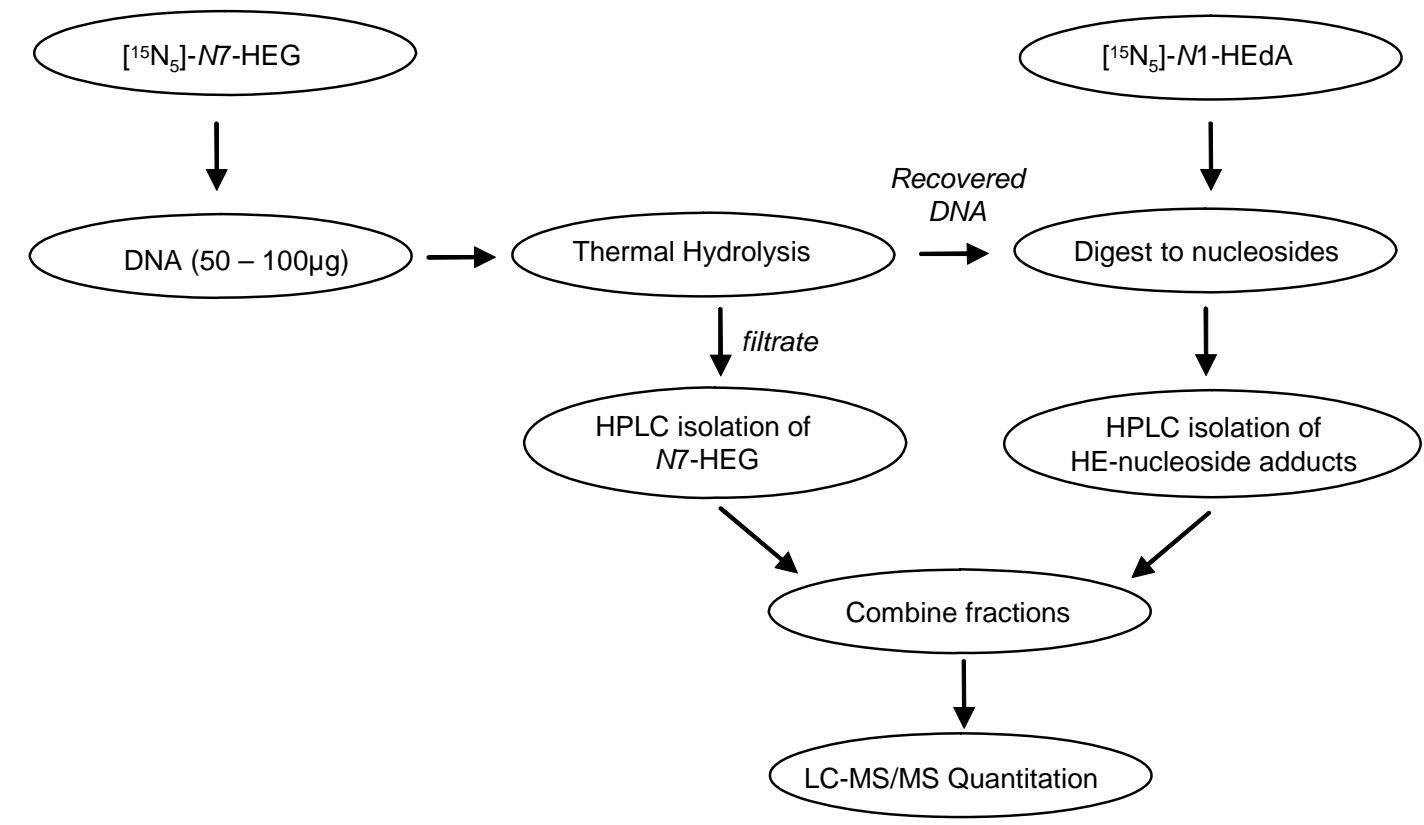

Figure 3: 


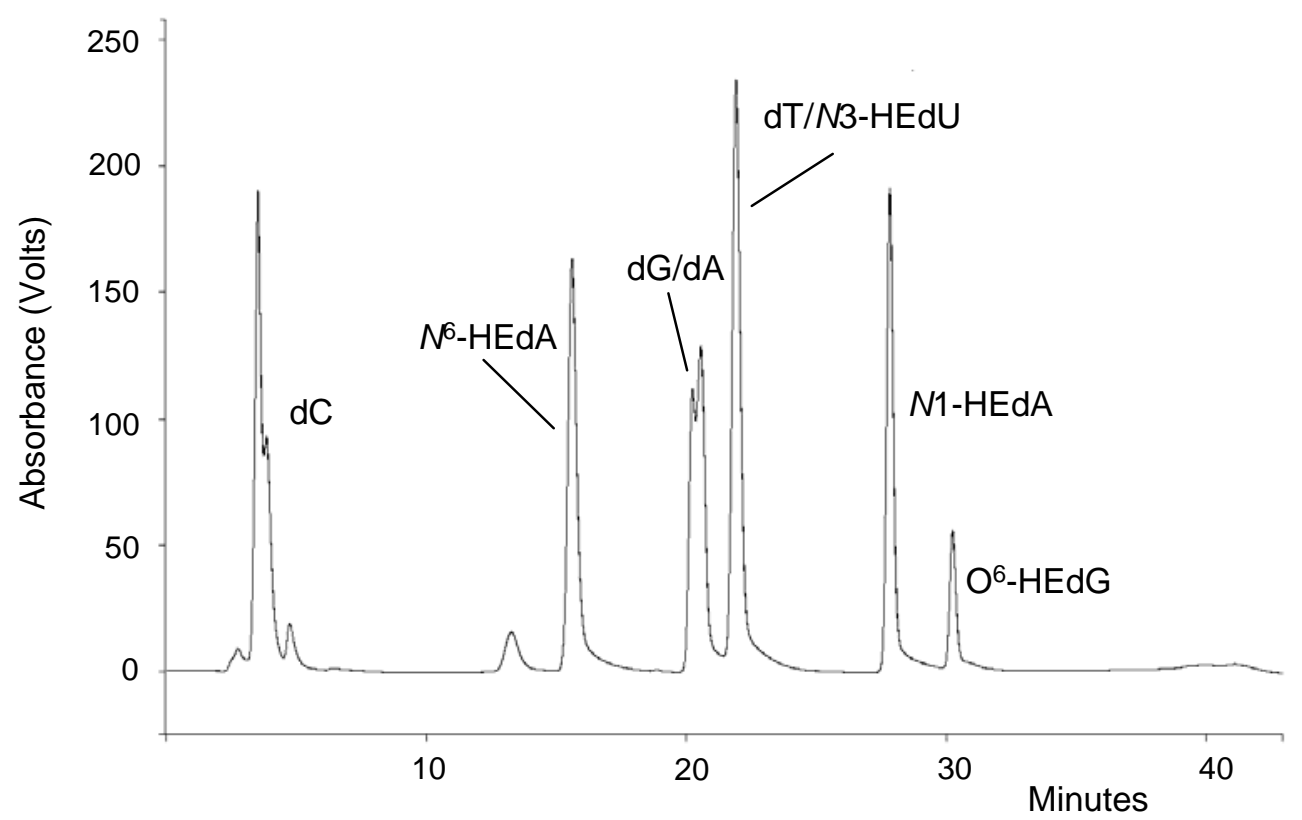

Figure 4: 

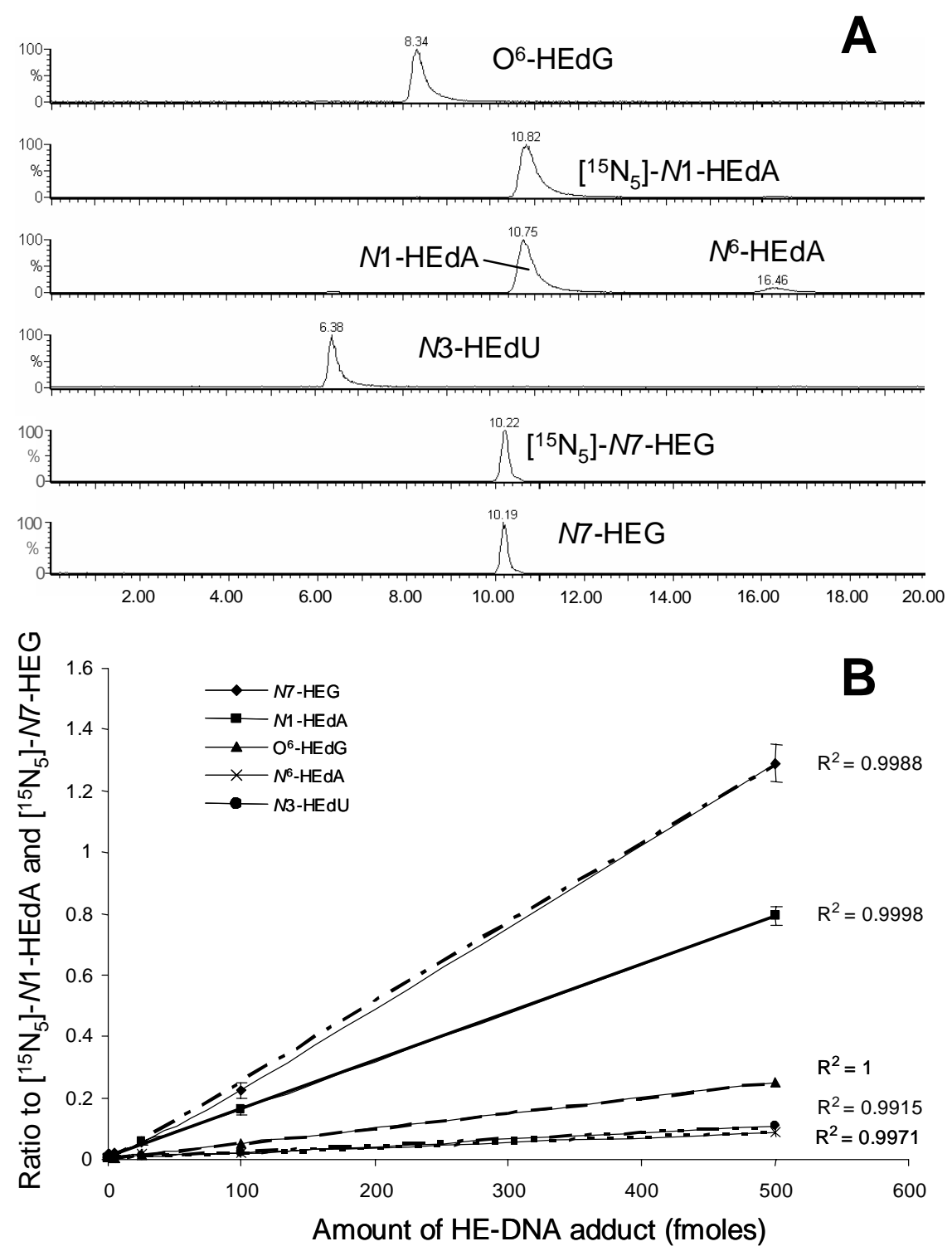

Figure 5: 

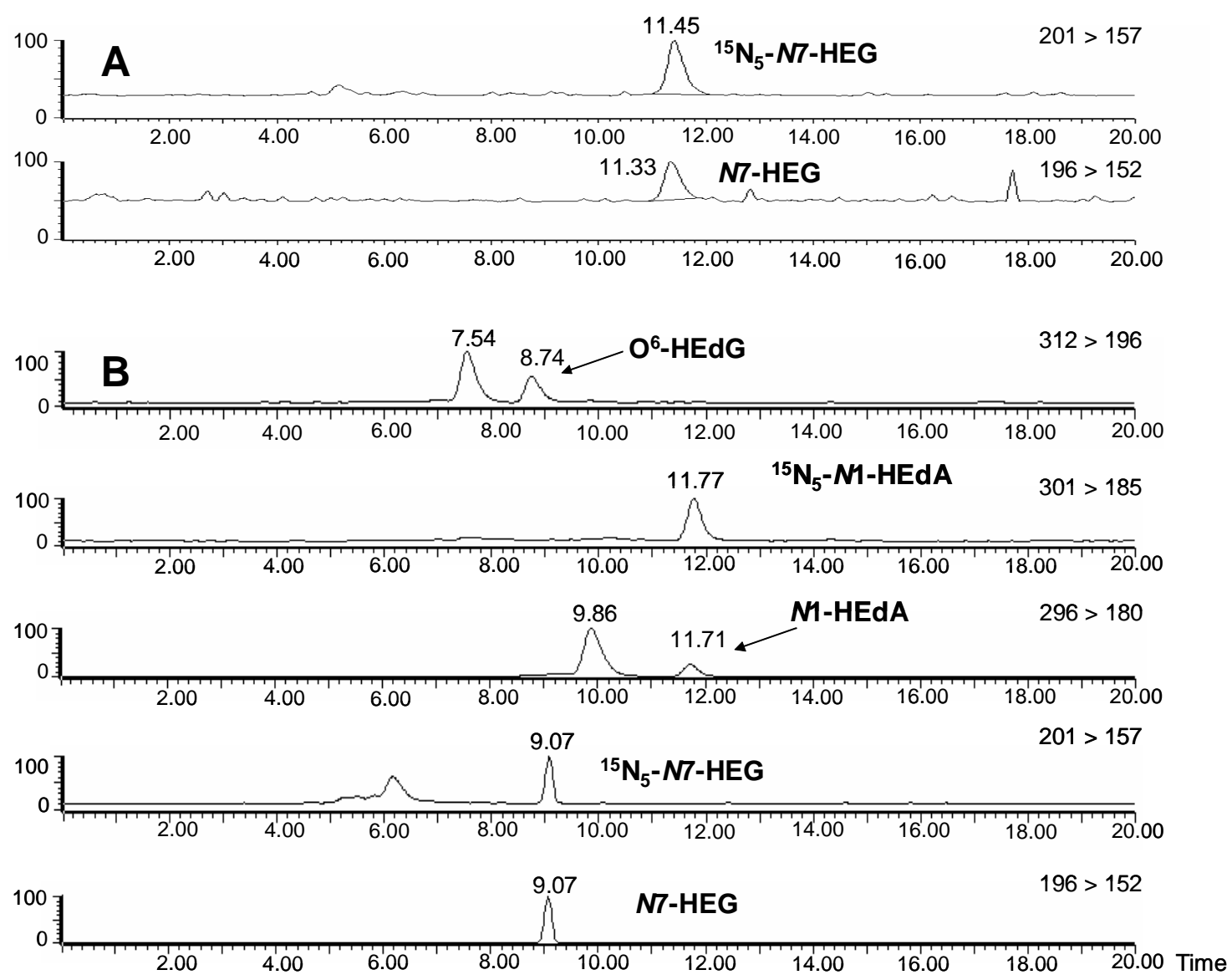

Figure 6: 
Table I. Representative adduct levels per $10^{8}$ nucleotides present in calf thymus, pSP189 plasmid and rat liver DNA, as measured by the LC-MS/MS assay. Results presented are from the duplicate analysis of a single sample for each type of DNA, and are reported as the mean value.

\begin{tabular}{l|ccc}
\hline \multicolumn{1}{c|}{ DNA sample } & \multicolumn{3}{c}{ Adducts/10 ${ }^{\mathbf{3}}$ nucleotides } \\
& N7-HEG & N1-HEdA & O $^{\mathbf{6}}$-HEdG \\
\hline Control rat liver & $8 \pm 1.5$ & $<$ LOD $^{*}$ & $<$ LOD \\
Calf thymus DNA & $59 \pm 1$ & $<$ LOD & $<$ LOD \\
EO exposed plasmid (10mM)** & $415166 \pm 19470$ & $24216 \pm 5967$ & $575 \pm 21$ \\
\hline
\end{tabular}

*Less than the limit of detection, this is approximately 1 adduct $/ 10^{9}$ for N1HEdA and 1 adduct $/ 10^{8}$ for $\mathrm{O}^{6}$-HEdG. $N^{6}$-HEdA and $N 3$-HEdU adducts were not detectable in any samples analysed. **Treatment with higher concentrations of EO resulted in a dose dependent increase in these adducts (data not shown). 


\section{REFERENCES}

1. IARC Monographs. Some Industrial Chemicals. 1994; 60,;73.

2. Segerbäck, D. Chemico Biological Interactions 1983; 45(2); 139.

3. Filser, J.G.; Denk, B.; Tornqvist, M.; Kessler, W.; Ehrenberg, L. Archives in Toxicology 1992; 66(3); 157.

4. Elfarra, A.A.; Duescher, R.J.; Pasch, C.M. Archives in Biophysical Biochemistry 1991; 286; 244.

5. Ehrenberg, L.; Hussein, S. Mutation Research 1977; 46(3); 196.

6. Leibermann, M.; Mapson, L.W. Nature. 1964; 204; 343.

7. Tornqvist, M.; Gustafsson, B.; Kautiainen, A.; Harms-Ringdahl, M.; Granath, F.; Ehrenberg, L. Carcinogenesis. 1989; 10; 39.

8. Kessler, W.; Remmer, H. Biochemical Pharmacology 1990; 39; 1347.

9. Clemens, M.R.; Einsele, H.; Frank, H.; Remmer, H.; Waller, H.D. Biochemical Pharmacology 1983; 32; 3877.

10. Nivard, M.J.M.; Czene, K.; Segerbäck, D.; Vogel, E.W. Mutation Research 2003; 529; 95. 
11. Walker, V.E.; Fennell, T.R.; Boucheron, J.A.; Fedtke, N.; Ciroussel, F.; Swenberg, J.A. Mutation Research 1990; 233; 151.

12. Kelsey, K.T.; Wiencke, J.K.; Eisen, E.A.; Lynch, D.W.; Lewis, T.R.; Little, J.B. Cancer Research 1988; 48(17); 5045.

13. Hogstedt, C.; Malmqvist, N.; Wadman, B. Journal of the American Medical Association 1979; 241; 1132.

14. Hogstedt C.; Aringer, L.; Gustavsson, A. Journal of the American Medical Association 1986; 255(12); 1575.

15. Teta. M.J.; Sielken. R.L.; Valdez-Flores. C. Risk Analysis 1999; 19; 1135.

16. Coggon, D.; Harris, E. C.; Poole, J.; Palmer K. T. Occupational and Environmental Medicine 2004; 61; 358.

17. Segerbäck, D. Carcinogenesis, 1990; 11(2); 307.

18. Li, F.; Segal, A.; Solomon, J.J. Chemico Biological Interactions 1992; 83; 35.

19. Lawley, P.D.; Brookes, P. Biochemical Journal 1963; 89; 127.

20. Takeshita, M.; Chang, C-H.; Johnson, F.; Will, S.; Grollman, A.P. Journal of Biological Chemistry 1987; 262(21); 10171.

21. Loeb, L.A.; Preston, B.D. Annual Reviews in Genetics 1986; 20; 201. 
22. Lawley, P.D. British Medical Bulletin 1980; 36(1); 19.

23. Solomon, J.J.; Mukai, F.; Fedyk, J.; Segal, A. Chemico Biological Interactions $1988 ; 67 ; 275$.

24. Solomon, J.J.; Segal, A. Environmental Health Perspectives 1989; 81; 19.

25. Bhanot, O.S.; Singh, U.S.; Soloman, J.J. Journal of Biological Chemistry 1994; 269(47); 30056.

26. Barlow, T.; Takeshita, J.; Dipple, D. Chemical Research in Toxicology 1998; 11; 838.

27. Gamboa da Costa, G.; Churchwell, M.I.; Hamilton, L.P.; Von Tungeln, L.S.; Beland, F.A.; Marques, M.M.; Doerge, D.R. Chemical Research in Toxicology 2003; 16; 1328.

28. Rusyn I.; Asakura, S.; Li, Y.; Kosyk, O.; Koc, H.; Nakamura, J.; Upton, P.B.; Swenberg, J.A. DNA Repair 2005; 4; 1099.

29. Loeppky, R. N.; Ye, Q.; Goelzer, P.; Chen, Y. Chemical Research in Toxicology $2002 ; 15 ; 470$. 
30. Eide, I.; Zhao, C.; Kumar, R.; Hemminki, K.; Wu, K-Y.; Swenberg, J.A. Chemical Research in Toxicology 1999; 12; 979.

31. Koivisto, P; Hemminki, K. Carcinogenesis 1990; 11(8); 1389.

32. Kumar, R.; Staffas, J.; Forsti, A.; Hemminki, K. Carcinogenesis 1995; 16(3); 483.

33. Kumar, R.; Hemminki. K. Carcinogenesis 1996; 17(3); 485.

34. Zhao, C.; Tyndyk, M.; Eide, I.; Hemminki, K. Mutation Research 1999; 424; 117.

35. van Delft, J.H.M.; van Winden, M.J.M.; Luiten-Scuite, A.; Ribiero, L.R.; Baan, R.A. Carcinogenesis 1994; 15(9); 1867.

36. Walker, V.E.; Fennell, T.R.; Upton, P.B.; Skopek, T.R.; Prevost, V.; Shuker, D.E.G.; Swenberg, J.A. Cancer Research 1992; 52; 4328.

37. Saha, M.; Abushamaa, A.; Giese, R.W. Journal of Chromatography A 1995; 712; 345.

38. Singh, R.; Farmer, P.B. Carcinogenesis, 2006; 27(2) 178.

39. Kao, C.-Y.; Geise, R.W. Chemical Research in Toxicology 2005; 18; 70. 
40. Plna, K.; Nilsson, R.; Koskinen, M.; Segerbäck, D. Carcinogenesis 1999; 20(10); 2025.

41. Tretyakova, N.Y.; Burney, S.; Pamir, B.; Wishnok, J.S.; Dedon, P.C.; Wogan, G.N.; Tannenbaum S.R. Mutation Research: Fundamental Molecular Mechanisms in Mutagenesis 2000; 447; 287.

42. Marsden, D.A.; Jones, D.J.L.; Lamb, J.H. Tompkins, E.M.; Farmer, P.B.; Brown, K. Chemical Research in Toxicology 2007, 20; 290.

43. McLuckie, K.I.E.; Crookston R.J.R.; Gaskell, M.; Farmer, P.B.; Routledge, M.N.; Martin E.A.; Brown, K. Biochemistry 2005; 44; 8198.

44. Brookes, P.; Lawley, P.D. Journal of the Chemistry Society 1960; 539.

45. Liao, P.-C.; Li, C-M.; Hung, C-W.; Chen, S-H. Journal of Mass Spectrometry 2001; 36; 336.

46. Wu, K.-Y.; Scheller, N.; Ranasinghe, A.; Yen, T-Y.; Sangaiah, R.; Giese, R.; Swenberg, J.A. Chemical Research in Toxicology 1999; 12; 722.

47. Nakao, L.S.; Fonseca, E.; Augusto, O. Chemical Research in Toxicology 2002; $15 ; 1248$.

48. Leclercq, L.; Laurent, C.; De Pauw, E. Analytical Chemistry 1997; 69; 1952. 
49. Brink, A.; Lutz, Y.; Volkel, W.; Lutz, W.K. Journal of Chromatography B 2006; 830; 255.

50. Churchwell, M.I.; Beland, F.A.; Doerge, D.R. Chemical Research in Toxicology $2002 ; 15 ; 1295$. 